\title{
Lethal Dose of Calcium Bentonite in Wistar Rats
}

\author{
Dwika Audiyananda, ${ }^{1}$ Hendro Sudjono Yuwono, ${ }^{2}$ Adria Adnan ${ }^{2}$ \\ ${ }^{1}$ Faculty of Medicine Universitas Padjadjaran, Indonesia, ${ }^{2}$ Department of Surgery Faculty of \\ Medicine Universitas Padjadjaran/Dr. Hasan Sadikin General Hospital Bandung, Indonesia, \\ ${ }^{3}$ Department of Biomedical Sciences Faculty of Medicine Universitas Padjadjaran, Indonesia
}

\section{Abstract}

Background: Calcium bentonite is a type of clay produced by a devitrification of volcanic ash which is often used as a traditional medicine to absorb toxins and waste products of metabolism. The aim of this study was to determine the lethal dose of calcium bentonite in Wistar rats to explore its toxicity level and safe use.

Methods: Fifty male and female Wistar rats were randomly divided into five groups for each sex. The control group was given $5 \mathrm{cc}$ aquadest whereas the other four groups received calcium bentonite solution of $50 \mathrm{mg} / \mathrm{kgBW}, 300 \mathrm{mg} / \mathrm{kgBW}, 2,000 \mathrm{mg} / \mathrm{kgBW}$, and 5,000 mg/kgBW, respectively, at a single dose. The weight was observed for up to 7 days and analyzed using the unpaired t-test and MannWhitney test. The death rate was calculated using the probit analysis. Median lethal dose results were then classified according to Loomis Criteria.

Results: No deaths occurred at the highest dose, suggesting that the median lethal dose value of calcium bentonite was $>5,000 \mathrm{mg} / \mathrm{kgBW}$. No weight loss occurred due to the administration of calcium bentonite and a significant increase in the body weight was even observed in the male rat group. Interestingly, a significant decrease was found in the female rats group when compared to the control group.

Conclusions: Calcium bentonite is classified as a practically non-toxic material with a median lethal dose of over $5,000 \mathrm{mg} / \mathrm{kgBW}$.

Keywords: Calcium bentonite, LD50, toxicity

\section{Introduction}

Traditional medicine has been often used for self-medication, however, health professionals are reluctant to use them since the efficacy of traditional medicine has not been scientifically proven and the safety of its usage in humans is still low. ${ }^{1}$ Clay is a type of drug derived from natural resources and has been used for generations. ${ }^{2}$ The type of clay often used as a treatment is calcium bentonite, smectite group mineral soil composed of $80 \%$ montmorillonite and calcium content. ${ }^{2,3}$

Calcium bentonite is made from mineral weathering and the hardening of the volcanic ash that occurs in the atmosphere of alkaline water. ${ }^{4}$ Calcium bentonite has a selective adsorption ability for a wide range of organic materials by maintaining their natural characteristics to match the $\mathrm{pH}$ of living things and have a surface containing negative electromagnetic. ${ }^{5,6}$ The adsorption properties of calcium bentonite depend on the form and surface width. The greater amount of surface area, the more chemical substances that can be bound and the pores can be completely filled in. The dry form of calcium bentonite has been widely used as an antiseptic and antidote for bacteria and chemical poisoning. ${ }^{2,7}$

Research on calcium bentonite safety is needed to develop bentonite into a phytopharmaca. One of the methods to determine the toxicity classification is based on the value of LD50 or median lethal dose of a substance. ${ }^{1,7}$ LD50 is a statistically calculated dose of a substance that causes death in $50 \%$

Correspondence: Dwika Audiyananda, Faculty of Medicine Universitas Padjadjaran, Jalan Raya Bandung-Sumedang Km. 21, Jatinangor, Sumedang, Indonesia, Email: dr.dwikaaudiyananda@gmail.com 
of the research subject. ${ }^{7}$ The aim of this study was to determine the median lethal dose of calcium bentonite in Wistar rats (Rattus novergicus), therefore, the toxicity level can be classified, as well as the safety usage.

\section{Methods}

This study was carried out from OctoberNovember 2012 in the Animal Laboratory of the Department of Pharmacology and Therapy Faculty of Medicine Universitas Padjadjaran. The protocol study was approved by the Research Ethics Committee Faculty of Medicine Universitas Padjadjaran no 204/ UN6.C2.1.2/KEPK/2012. Calcium bentonite was obtained from the Chemical Laboratory, Faculty of Mathematics and Science Education, Universitas Pendidikan Indonesia that was taken from Karangnunggal, Tasikmalaya, Jawa Barat, Indonesia. Laboratory tests were performed to confirm the accuracy of the calcium bentonite substance at the Chemistry Laboratory, Bandung Institute of Technology.

Fifty healthy male and female Wistar rats (Rattus novergicus) aged 8-12 weeks old and $200 \pm 50 \mathrm{~g}$ weight were used. All rats were housed in a homogenous temperature and dark-light cycle for 7 days with ad libitum access to food and drink. Calcium bentonite powder was weighed using digital scales in accordance with the dose of each treatment group and further dissolved in aquadest of 5 ccs. The Wistar rats have fasted for 24 hours before the administration of calcium bentonite. $^{8}$

The rats were randomly divided into five groups for each sex. The control group was given 5 cc aquades and four other groups received a single dose of calcium bentonite solution given per sonde with a dosage of 50 $\mathrm{mg} / \mathrm{kgBW}, 300 \mathrm{mg} / \mathrm{kgBW}, 2,000 \mathrm{mg} / \mathrm{kgBW}$, and 5,000 mg/kgBW, respectively. ${ }^{7}$ The routine weighing was conducted in all Wistar rats for up to 7 days after treatment and the standard food after the treatment was given.

All dead rats were counted after the administration of a single dose of calcium bentonite. Data from the dead animals were calculated using probit analysis and then the results were classified into the toxicity criteria based on Loomis. ${ }^{8}$

Normality and homogeneity of the body weight data were tested using the SaphiroWilk. Data between treatment groups and a control group were statistically analyzed using unpaired T-Test and Mann Whitney.

\section{Results}

There were no deaths in both male and female rats up to 7 days after the administration up to the highest dose of 5,000 mg/kgBW at a single dose of oral calcium bentonite. Therefore, the graphic from probit analysis for this study was not available. Similiarly, the LD50 value of a single dose of calcium bentonite could not be calculated because as there were no dead rats.

The body weight in male and female rats from routine weighing in 7 days was depicted

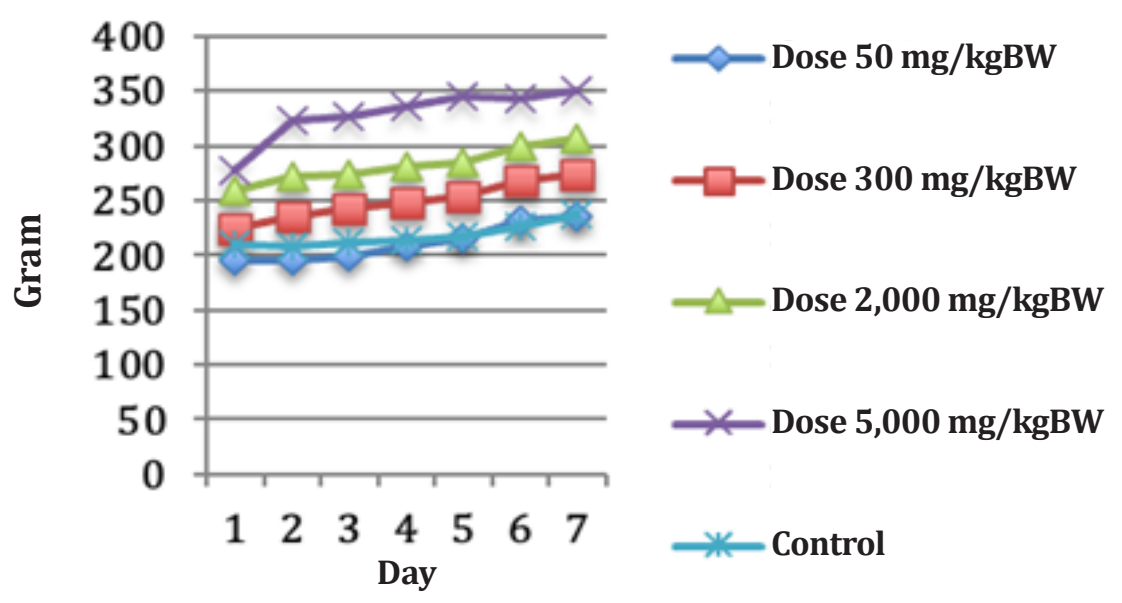

Figure 1 Changes of Mean Body weight (g) in Male Rats Observed in 7 days After a Singledose of Oral Calcium Bentonite 


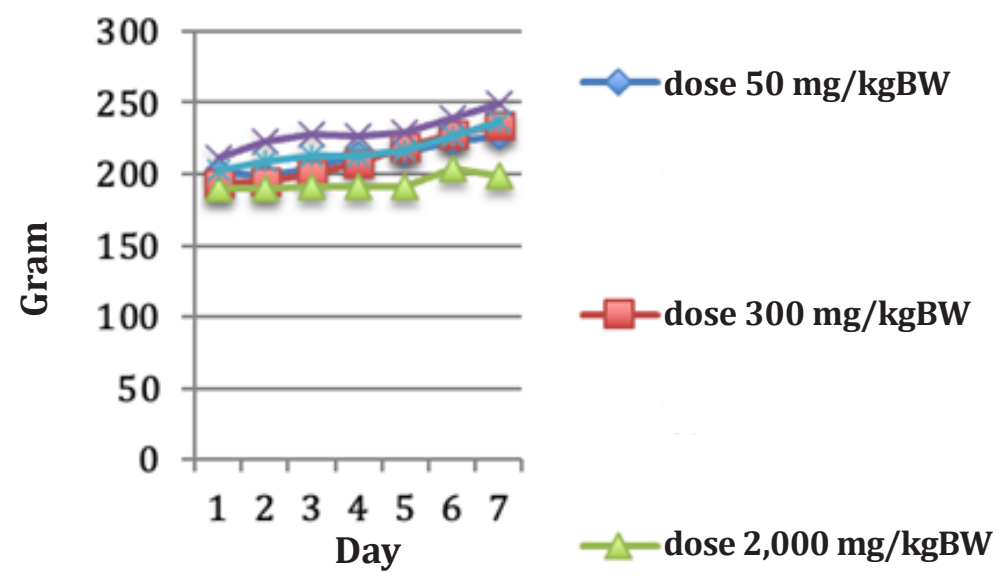

Figure 2 Changes of Mean Body weight (g) in Female Rats Observed in 7 days After a Singledose of Oral Calcium Bentonite

in Figure 1 and 2 . All of the groups gained weight and there was no decrease in body weight by $10 \%$ from the initial weight.

Shapiro-Wilk test or Normality test results showed abnormal distribution in male group data $(\mathrm{p}<0.05)$ and normal distribution for female group data $(p>0.05)$. Compared to control group, male rats had significant different in body weight using dose of 300 ,
2,000 and 5,000 $\mathrm{mg} / \mathrm{kgBW}$ with significance of $\mathrm{p}=0.047,0.009$, and 0.009 respectively as shown in Table 1 . On the contrary, a significant decrease was observed in the average body weight of female rats between group 3 compared with the control group (193.6 \pm 14.74 vs $216.60 \pm 15.14 ; p=0.041)$, whereas no significant difference, with other groups.

Table 1 Body Weight among Male Rats in Treatment Groups compared with the Control Group

\begin{tabular}{lcc}
\hline & Median (minimum-maximum) & P value \\
\hline Group 1 dose $50 \mathrm{mg} / \mathrm{kgBW}$ & $212(187-248)$ & 0.465 \\
Group 2 dose $300 \mathrm{mg} / \mathrm{kgBW}$ & $237(187-248)$ & $0.047^{*}$ \\
Group 3 dose $2,000 \mathrm{mg} / \mathrm{kgBW}$ & $272(265-306)$ & $0.009^{*}$ \\
Group 4 dose $5,000 \mathrm{mg} / \mathrm{kgBW}$ & $324(308-351)$ & $0.009^{*}$ \\
Group 5 control & $221(198-236)$ & \\
\hline
\end{tabular}

Note: P-value comparing the group with control group unpaired t-test. * statistically different compared with the control group

Table 2 Body Weight among Female Rats in Treatment Groups compared with the Control Group

\begin{tabular}{lcc}
\hline & $\begin{array}{c}\text { Body weight } \\
\text { Mean } \pm \text { S.D }\end{array}$ & P-value \\
\hline Group 1 dose $50 \mathrm{mg} / \mathrm{kgBW}$ & $211.80 \pm 9.41$ & 0.564 \\
Group 2 dose $300 \mathrm{mg} / \mathrm{kgBW}$ & $211 \pm 20.63$ & 0.638 \\
Group 3 dose $2,000 \mathrm{mg} / \mathrm{kgBW}$ & $193.6 \pm 14.74$ & $0.041^{*}$ \\
Group 4 dose $5,000 \mathrm{mg} / \mathrm{kgBW}$ & $229.20 \pm 12.56$ & 0.190 \\
Group 5 control & $216.60 \pm 15.14$ & \\
\hline
\end{tabular}

Note: P-value comparing the group with control group unpaired t-test. * statistically different compared with the control group 


\section{Discussion}

Our study has explored the lethal dose of calcium bentonite in Wistar rats (Rattus novergicus), resulting in no difference of LD50 value between male and female rats, thus all subjects have the same sensitivity to the material and no gender variation. ${ }^{10}$ Furthermore, it is apparent that LD50 of calcium bentonite $>5,000 \mathrm{mg} / \mathrm{kgBW}$ has been shown as practically non-toxic materials according to Loomis Criteria. ${ }^{8}$

After 7 days of administration of singledose oral calcium bentonite, there is an increase in body weight daily (Figure 1 and 2). Furthermore, calcium bentonite has no toxic effect on the growth and development of the Wistar rats' body weight. The substances would have significant side effects if there is a weight loss of more than $10 \%$ from their baseline and significant differences or changes of body weight between treatment groups compared with the control group. . $^{8,10}$

Interestingly, we found a significant increase in the average body weight between group 2 (dose $300 \mathrm{mg} / \mathrm{kgBW}$ ), group 3 (dose $2,000 \mathrm{mg} / \mathrm{kgBW}$ ), and group 4 (dose 5,000 $\mathrm{mg} / \mathrm{kgBW}$ ) compared with the control group $(\mathrm{p}<0.05)$, suggesting that a single dose of oral calcium bentonite does not suppress appetite and do not interfere with the metabolism of nutrients coming from food or drink. ${ }^{12}$

However, there is a significant decrease in the average body weight in female rat groups between group 3 (dose 2,000 mg/kgBW) compared with the control group, but routine measurement showed there was no body weight loss of more than $10 \%$ from the initial weight in that group. Therefore, body weight loss is not affected by the administration of calcium bentonite and probably due to the hormonal and metabolic effects of female rats. ${ }^{10}$

Our findings are consistent with the safety data sheet from the ThermoFisher Scientific and the Carl Roth Company, in which the LD50 value of oral bentonite is more than $5,000 \mathrm{mg} /$ kgBW. ${ }^{11,12}$ Substances with LD50 values higher than $5,000 \mathrm{mg} / \mathrm{kgBW}$ by the oral route are regarded as being safe or practically non-toxic based on Loomis criteria. ${ }^{8,12}$

The available studies on the toxicity of calcium bentonite indicate that the principal exposure pathway of concern is the inhalation of respirable dust by occupationally exposed cohorts. Bentonite itself is probably not more toxic than any other particulate not otherwise regulated. It is not classified as a carcinogen by any regulatory or advisory committee, but some bentonite may contain variable amounts of respirable crystalline silica, a recognized human carcinogen. However, the data have too many limitations to estimates the side effect of calcium bentonite for humans at current exposure levels. ${ }^{13}$

Several studies have been conducted to study the effects of oral exposure of bentonite to humans. For example, the safety of bentonite has been evaluated when administered to protect the human gastrointestinal system from the adverse effects of aflatoxins. The used calcium bentonite was tested on a group of volunteers to determine the safety and tolerance of the clay itself during a shortterm experiment. The results demonstrate the relative safety of such material in human beings for example only mild gastrointestinal effects such as abdominal pain, bloating, constipation, diarrhea, and flatulence have been reported in some participants after receiving 1.5 and $3 \mathrm{~g} /$ day for a period of 2 weeks. No significant dosedependent effects were observed for blood chemistry. ${ }^{14}$ Literature review by Moosavi ${ }^{4}$ on 2,500 scientific articles published in PubMed has shown that the effect of the clay on various organs of the body, resulting in no side effects of clay when used with the right dose.

There are several limitations to this study. First, histopathological examination of animal organs such as liver or kidneys were not performed, therefore, the effects of toxicity on a microscopically are not known. Second, there were no observations of toxicity symptoms were carried out, including motor activity, condition of the tail, feathers, eyes, heart, lungs, nasal secretions, body temperature, salivation, defecation, and urination due to limited tools for assessing these symptoms.

In conclusion, present data suggest that a single-dose of oral calcium bentonite has LD50 more than 5,000 mg/kgBW and classified as practically nontoxic materials based on Loomis criteria. Future studies should clarify the safe usage of multiple-dose of calcium bentonite to explore the prolonged toxic effect of the substance.

\section{References}

1. Bhusnure OG, Shinde MC, Vijayendra SSM, Gholve SB, Giram PS, Birajdar MJ. Phytopharmaceuticals: an emerging platform for innovation and development of new drugs from botanicals. JDDT. 2019;9(3-s):1046-57.

2. Gomes CF, Gomes JH, da Silva EF. 
Bacteriostatic and bactericidal clays: an overview. Environ Geochem Health. 2020;42(11):3507-27.

3. Behroozian S, Svensson SL, Li LY, Davies JE. Broad-spectrum antimicrobial and antibiofilm activity of a natural clay mineral from British Columbia, Canada. mBio. 2020;11(5):e02350-20.

4. Moosavi M. Bentonite clay as a natural remedy: a brief review. Iran J Public Health. 2017;46(9):1176-83.

5. Maisanaba S, Pichardo S, Puerto $M$, Gutiérrez-Praena D, Cameán AM, Jos A. Toxicological evaluation of clay minerals and derived nanocomposites: A review. Environ Res. 2015;138:233-54.

6. Massaro M, Noto R, Riela S. Past, present and future perspectives on halloysite clay minerals. Molecules. 2020;25(20):4863.

7. Barile FA. Clinical toxicology: principle and mechanisms. $3^{\text {rd }}$ ed. Boca Raton: CRC Press; 2019.

8. Loomis TA, Hayes AW. Loomis's essential of toxicology. $5^{\text {th }}$ ed. San Diego: Academic Press; 2019.

9. World Health Organization Regional Office for the Western Pacific. Research guidelines for evaluating the safety and efficacy of herbal medicines. Manila: WHO Regional
Office for the Western Pacific; 1993 [cited 2021 June 6] Available from: https://apps. who.int/iris/handle/10665/207008.

10. Jothy SL, Zakaria Z, Chen Y, Lau YL, Latha LY, Sasidharan S. Acute oral toxicity of methanolic seed extract of cassia fistula in mice. Molecules. 2011; 16(6):5268-82.

11. ThermoFisher Scientific. Safety data sheet bentonite powder. Loughborough, UK; 2020 [cited 2021 June 27] Available from: https://www.fishersci. co.uk/chemicalProduct Data_uk/ wercs?itemCode $=\mathrm{B} / 1300 / 60$

12. Carl Roth GmbH+Co KG. Safe work Australia- code of practice: safety data sheet of bentonite pure. Schoemperlenstr, Karlsruhe, Germany; 2020 [cited 2021 June 27] Available from: https://carlroth. com > medias > SDB-0113-AU-EN.pdf

13. Maxim LD, Niebo $R$, McConnell EE. Bentonite toxicology and epidemiology a review. Inha Toxicol. 2016;28(13):591617.

14. Mitchell NJ , Kumi J, Aleser M, Elmore SE, Rychlik KA, Zychowski KE, et al. Shortterm safety and efficacy of calcium montmorillonite clay (UPSN) in children. Am J Trop Med Hyg. 2014 ;91(4):777-85. 